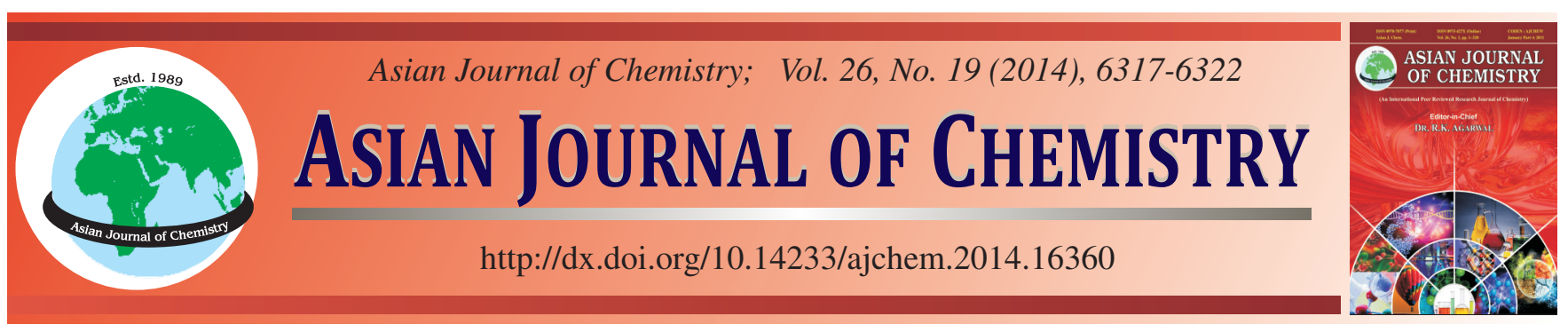

\title{
Effects of Acid Treatments on Surface Property and Mercury Removal Performance of Lignite Semi-coke
}

Huawei Zhang ${ }^{*}$, Xiuli Liu, Li Wang and Peng Liang

College of Chemical and Environmental Engineering, Shandong University of Science and Technology, Qingdao 266510, Shandong Province, P.R. China

*Corresponding author: Tel/Fax: +86 532 86057620; Tel: +86 13806399945; E-mail: sdkdzhw@163.com

Received: 13 September 2013; $\quad$ Accepted: 30 December 2013; $\quad$ Published online: 16 September 2014; $\quad$ AJC-15909

\begin{abstract}
In this study, hydrochloric acid, nitric acid and sulfuric acid are, respectively applied to lignite semi-coke from Inner Mongolia for surface modification processing and the effects of various acid treatments on the lignite semi-coke surface property and mercury removal performance are observed. The results show that the acid treatments have significant effects on the specific surface area, aperture structure, surface chemical functional group and other physical and chemical properties. In addition, the micropore ratio and pore volume of semi-coke are the major factors determining the mercury removal efficiency at low temperature; the surface oxygen-containing functional groups (carboxyl, lactone, phenolic hydroxy, etc.), the positively charged nitrogenous functional groups and the other heteroatom functional groups are the active sites of gaseous $\mathrm{Hg}^{0}$ catalytic oxidation reactions and determine the mercury removal efficiency of semi-coke at high temperature. It is shown that the cellular structure of the nitric acid modified semi-coke is the most highly developed and has a strong mercury removal performance at $30{ }^{\circ} \mathrm{C}$. The hydrochloric acid treatment leaves a $\mathrm{Cl}-\mathrm{C}-\mathrm{Cl}$ functional group which may easily react with gaseous $\mathrm{Hg}^{0}$ on the surface of semi-coke, causes the carboxyl and phenolic hydroxy contents to increase and greatly improves the mercury removing efficiency of lignite semi-coke at $140{ }^{\circ} \mathrm{C}$.
\end{abstract}

Keywords: Lignite semi-coke,Gaseous $\mathrm{Hg}^{0}$, Acid treatment, Mercury removal efficiency.

\section{INTRODUCTION}

As a heavy metal severely damaging the environment and human health, treatment technology concerning mercury has been a hot topic in recent studies around the world. The coal burning industry is the principal emission source of the pollutant mercury, accounting for approximately $46 \%$ of the man-made discharge ${ }^{1,2}$. Active carbon is a common adsorbing material of gaseous $\mathrm{Hg}^{0}$ in coal-fired flue gas and relevant studies have mainly focused on the following aspects. The physical and chemical method modification of active carbon, $\mathrm{Hg}^{0}$ adsorption mechanism of various active carbons and engineering applications in flue gas treatment of coal-fired power plants ${ }^{3-6}$.

Lignite semi-coke has surface properties which are similar to those of active carbon, but is sold at only $50 \%$ or so of the price of active carbon, therefore it is widely used as an inexpensive adsorbing material in the fields of flue gas desulfurization and denitrification, oil purification and sewage treatment. However, few studies regarding the gaseous $\mathrm{Hg}^{0}$ adsorbents in coal-fired flue gas have been reported. Preliminary studies have shown ${ }^{7,8}$ that for gaseous $\mathrm{Hg}^{0}$ adsorption and reaction on the semi-coke surface, its physical adsorption process is related to the specific surface area, pore structure and other physical structures of the semi-coke. In addition, its chemical adsorption process is affected by chemical properties such as the oxygencontaining functional group, nitrogen-containing functional group and other heteroatom functional groups found on the semi-coke surface.

Modification treatment is conducted on carbon-based materials using various acids, which may significantly change the physico-chemical properties of their surfaces. Previous studies ${ }^{9}$ have shown that after lignite semi-coke is treated with nitric acid, its specific surface area and pore volume will increase by a certain degree and that the de-ashing of nitric acid may generate abundant new pores on the semi-coke surface, thus enabling the semi-coke to possess an ample knitmesh structure. Zhou et al. ${ }^{10}$ made an FTIR analysis and Boehm titration on active carbon before and after the modification of $\mathrm{HCl}, \mathrm{HNO}_{3}$ and $\mathrm{H}_{2} \mathrm{SO}_{4}$ and discovered that after treatment, the contents of functional groups such as carboxyl and the phenolic hydroxyl group on the active carbon surface tended to increase.

The present paper, respectively adopts three common acids, namely $\mathrm{HCl}, \mathrm{HNO}_{3}$ and $\mathrm{H}_{2} \mathrm{SO}_{4}$, to conduct modification treatment for crude semi-coke, uses analysis methods such as elemental analysis, specific surface area analysis, Fourier 
transform infrared spectrum (FT-IR) and Boehm titration to analyze the effects of the acid treatment process on the physicochemical property on the semi-coke surface, then observes the mercury removal property of the modified semi-coke on a small fixed bed reactor and finally, studies the mercury removal mechanism of various acid treatments on the semi-coke.

\section{EXPERIMENTAL}

Sample preparation: The lignite semi-coke used in the tests is from the Huolin River of Inner Mongolia. The preparation method is as follows: Place a coal sample in a $700{ }^{\circ} \mathrm{C}$ muffle furnace, conduct $1 \mathrm{~h}$ of destructive distillation under anoxic conditions, cool it to room temperature, then smash it to 80 to 100 meshes for use and record as NM-SC; next, soak $10 \mathrm{~g}$ of prepared NM-SC for $24 \mathrm{~h}$ into mass fractions of $40 \%$ $\mathrm{H}_{2} \mathrm{SO}_{4}, 40 \% \mathrm{HNO}_{3}$ and $20 \% \mathrm{HCl}$ solution, with a 1:3 of solidliquid ratio; after the reactions are complete, filtrate and dry the samples and the semi-coke treated with the three acids may be obtained, which are recorded as S-SC, N-SC and Cl-SC.

Characterization of samples: The physical characterizations of the samples are analyzed by the Brunauer-EmmettTeller (BET) method and the surface area and pore size distribution are obtained by adsorbing and desorbing in $\mathrm{N}_{2}$ at $77 \mathrm{~K}$, using an automatic volumetric multipoint apparatus (SSA4300). Before the measurements are taken, all of the samples are outgassed at $100{ }^{\circ} \mathrm{C}$ for $2 \mathrm{~h}$. Nicolet 380 is adopted to observe the infrared spectroscopic analysis in the wavelength coverage range of 4000-400 $\mathrm{cm}^{-1}$.

Experimental methodology and instrumentation: In the laboratory, the adsorption equipment, a small stationary bed described by Zhang et $a l^{7}$, is used to evaluate the mercury removal property of the adsorption material semi-coke under the simulated flue gas condition. The adsorption efficiency is then used to determine the adsorption property index of the semi-coke. The computation method is shown as formula (1):

$$
\eta=1-\mathrm{C}_{\mathrm{t}} / \mathrm{C}_{0}
$$

where $\eta$ indicates adsorption efficiency, $\mathrm{C}_{0}$ is the initial concentration of gaseous $\mathrm{Hg}^{0}$ and $\mathrm{C}_{\mathrm{t}}$ indicates the concentration of gaseous $\mathrm{Hg}^{0}$ after adsorption.

\section{RESULTS AND DISCUSSION}

Table- 1 depicts the industrial and elemental analysis data of the crude semi-coke and those treated with various acids. It may be seen that the ash content of the semi-coke treated with the three acids is sharply reduced, in which the reduction rate of the ash content in semi-coke treated with $\mathrm{HCl}$ is the largest, followed by those treated with $\mathrm{HNO}_{3}$ and $\mathrm{H}_{2} \mathrm{SO}_{4}$. Hydrochloric acid may penetrate into the interior of the semi-coke particles and react with elements such as $\mathrm{Si}, \mathrm{Fe}, \mathrm{Al}$ and $\mathrm{Ca}$ in semicoke ash, thus enabling most ash to translate into soluble metal chloride. Therefore, the $\mathrm{HCl}$ treatment may sharply reduce the ash content in the semi-coke. With oxidability, $\mathrm{HNO}_{3}$ and $\mathrm{H}_{2} \mathrm{SO}_{4}$ may remove the partial ash content in the semi-coke, such as mineral substances including elements $\mathrm{Na}, \mathrm{K}, \mathrm{Ca}, \mathrm{Fe}$ and $\mathrm{Al}$. However, they have a low efficiency in removing $\mathrm{SiO}_{2}$ with a higher content, therefore the de-ashing performance is lower than that of $\mathrm{HCl}$.
After the $\mathrm{HCl}$ treatment is complete, the volatile content of the semi-coke slightly increases, the fixed carbon content increases more sharply and the contents of the four elements $\mathrm{O}, \mathrm{H}, \mathrm{N}$ and $\mathrm{S}$ are shown to be basically stable in the results of elemental analysis; after the $\mathrm{HNO}_{3}$ and $\mathrm{H}_{2} \mathrm{SO}_{4}$ treatment, the volatile content of the semi-coke and the contents of elements $\mathrm{O}, \mathrm{N}$ and $\mathrm{S}$ show clear increases, which illustrates that abundant oxygen-containing, nitrogen-containing and sulfur-containing chemical functional groups are shaped on the semi-coke surface during the $\mathrm{HNO}_{3}$ and $\mathrm{H}_{2} \mathrm{SO}_{4}$ treatment process.

\begin{tabular}{lcccccccccc}
\multicolumn{10}{c}{ TABLE-1 } \\
\multicolumn{10}{c}{ INDUSTRIAL AND ELEMENTAL ANALYSIS OF } \\
CRUDE AND ACID MODIFIED SEMI-COKE \\
\hline \multirow{2}{*}{ Sample } & $\begin{array}{c}\mathrm{M}_{\mathrm{ad}} \\
(\%)\end{array}$ & $\begin{array}{c}\mathrm{A}_{\mathrm{ad}} \\
(\%)\end{array}$ & $\begin{array}{c}\mathrm{V}_{\mathrm{ad}} \\
(\%)\end{array}$ & $\begin{array}{c}\mathrm{FC}_{\mathrm{ad}} \\
(\%)\end{array}$ & $\begin{array}{c}\mathrm{C}_{\mathrm{ad}} \\
(\%)\end{array}$ & $\begin{array}{c}\mathrm{H}_{\mathrm{ad}} \\
(\%)\end{array}$ & $\begin{array}{c}\mathrm{O}_{\mathrm{ad}} \\
(\%)\end{array}$ & $\begin{array}{c}\mathrm{N}_{\mathrm{ad}} \\
(\%)\end{array}$ & $\begin{array}{c}\mathrm{S}_{\mathrm{ad}} \\
(\%)\end{array}$ \\
\hline NM-SC & 2.60 & 24.26 & 7.46 & 65.87 & 66.93 & 1.47 & 3.30 & 1.22 & 0.22 \\
$\mathrm{Cl}-\mathrm{SC}$ & 2.08 & 6.45 & 9.17 & 82.30 & 67.54 & 1.66 & 3.28 & 1.31 & 0.19 \\
N-SC & 1.97 & 8.74 & 12.38 & 76.91 & 65.89 & 1.53 & 7.62 & 3.07 & 0.21 \\
$\mathrm{~S}-\mathrm{SC}$ & 2.01 & 10.32 & 10.98 & 76.69 & 66.41 & 1.65 & 7.14 & 1.25 & 2.11 \\
\hline
\end{tabular}

Analysis of specific surface area and pore structure: From the data shown in Table-2, the specific surface area and pore structure analysis of crude semi-coke and those treated with various acids, it may be seen that various acid treatment processes differ in their effects on the specific surface area and pore structure of the semi-coke. After $\mathrm{HCl}$ treatment, the specific surface area and total pore volume of the semi-coke increase slightly compared with those of the crude semi-coke. However, the $\mathrm{HCl}$ treatment only increases the volumes of the mesopore and macropore; in the meantime, it also gives rise to the partial transition of the micropores to mesopore and mesoporous. The $\mathrm{HNO}_{3}$ treatment may clearly increase the specific surface area and total pore volume of the semi-coke. Compared with crude semi-coke, the specific surface area and total pore volume of treated semi-coke, respectively increase by 109.6 and $62.6 \%$, the average pore size of modified semicoke decreases slightly and its surface micropore proportion increases slightly. Nitric acid treatment primarily increases the micropore number and micropore volume and has no effect on the numbers of mesopores or macropores, or on the pore volume. After the $\mathrm{H}_{2} \mathrm{SO}_{4}$ treatment, the specific surface area and total pore volume of the semi-coke, respectively decrease by 46.9 and $60.7 \%$, the average pore size considerably increases and the surface micropore proportion and micropore volume decrease dramatically. Sulfuric acid treatment process damages the surface micropore structure of the semi-coke, enabling the partial micropores to disappear or translate into mesopores and macropores.

Analysis of fourier transform infrared spectrum (FTIR): It may be seen from Fig. 1 that there are large differences in the infrared spectrograms of the semi-coke treated with various acids and the infrared spectrogram of the semi-coke treated with hydrochloric acid is similar to that of the crude semicoke, but the absorption peak intensity drastically enhances under the coverage of 3750 to $3100 \mathrm{~cm}^{-1}$, which indicates that the hydrochloric acid treatment enables the content of the -OH functional group on the semi-coke surface to increase. In addition, new absorption peaks appear at wave numbers 1068.37, 1176.36 and $1282.43 \mathrm{~cm}^{-1}$ for the semi-coke treated with nitric 
acid which belongs to the stretching vibration characteristic peak of the functional group, such as $\mathrm{COO}, \mathrm{C}-\mathrm{O}-\mathrm{C}$ and $\mathrm{COH}$ in the carboxylic acid, acid anhydride, the inner ester group and the phenolic hydroxyl group. According to the surface acid base titration and Boehm titration results shown in Table2 , it may be concluded that the nitric acid treatment increases the content of the acid functional groups such as carboxyl and the phenolic hydroxyl on the semi-coke surface. The peak at wave number $1347.99 \mathrm{~cm}^{-1}$ is a characteristic peak of structures such as nitrogen-containing compound pyridine, pyridine-Noxide, pyrone and that at wave number $2080.81 \mathrm{~cm}^{-1}$ is the characteristic absorption peak of the $\mathrm{C}=\mathrm{N}$ group, which indicates that the nitric acid treatment may increase the content of the nitrogen-containing functional group at the semi-coke surface. The absorption peak intensity under the coverage of 3750 to $3100 \mathrm{~cm}^{-1}$ of the semi-coke treated with sulfuric acid increases and the $\mathrm{C}=\mathrm{O}$ and $\mathrm{C}=\mathrm{C}$ stretching vibration peak increase at wave number $1525.42 \mathrm{~cm}^{-1}$, which indicates that the sulfuric acid treatment leads to the content increase of the functional groups such as hydroxyl, carboxyl, carbonyl and benzoquinonyl on the semi-coke surface. In addition, a characteristic peak of the sulfonic acid group appears at wave number $1382.71 \mathrm{~cm}^{-1}$, which indicates that the sulfuric acid treatment process generates the $-\mathrm{SO}_{3} \mathrm{H}$ functional group.

\begin{tabular}{|c|c|c|c|c|c|c|c|}
\hline \multicolumn{8}{|c|}{$\begin{array}{c}\text { TABLE-2 } \\
\text { SURFACE AREA AND PORE STRUCTURE ANALYSIS OF } \\
\text { CRUDE AND ACID MODIFIED SEMI-COKE }\end{array}$} \\
\hline \multirow[b]{2}{*}{ Sample } & \multirow{2}{*}{$\begin{array}{c}\text { BET } \\
\text { surface } \\
\text { area } \\
\left(\mathrm{m}^{2} / \mathrm{g}\right) \\
\end{array}$} & \multirow{2}{*}{$\begin{array}{c}\text { Average } \\
\text { pore } \\
\text { size } \\
(\mathrm{nm})\end{array}$} & \multicolumn{3}{|c|}{ Pore volume $\left(\mathrm{m}^{3} / \mathrm{g}\right)$} & \multicolumn{2}{|c|}{ Proportion $(\%)$} \\
\hline & & & Total & $\begin{array}{l}\text { Micro } \\
(\leq 2 \mathrm{~nm})\end{array}$ & Macro & $\begin{array}{l}\text { Micro } \\
(\leq 2 \mathrm{~nm})\end{array}$ & Macro \\
\hline NM-SC & 84.203 & 2.55 & 0.107 & 0.0775 & 0.0295 & 72.4 & \\
\hline Cl-SC & 97.278 & 2.96 & 0.113 & 0.0704 & 0.04 & 62 & \\
\hline & 176.52 & 2.4 & 0.174 & & & & \\
\hline S-SC & 44.662 & 10.08 & 0.042 & 0.0203 & 0.0217 & 48.3 & 51.7 \\
\hline
\end{tabular}

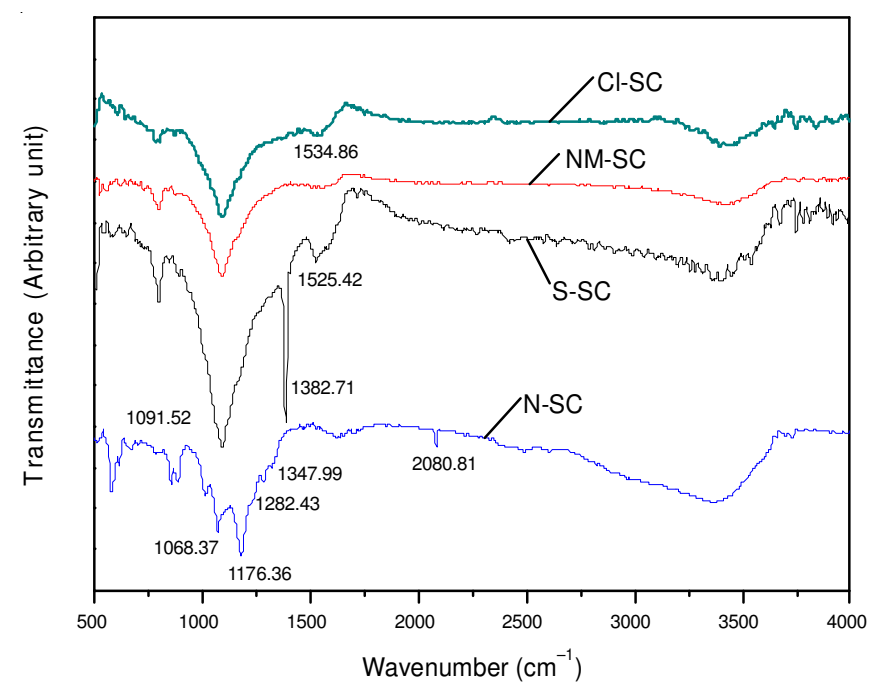

Fig. 1. FTIR analysis spectrogram of crude semi-coke and semi-coke treated with acids

Analysis of surface acid base titration and Boehm titration: The surface acid base titration and Boehm titration analysis is performed using the reported method ${ }^{11}$. The acidity of the oxygen-containing functional group on the semi-coke surface is as follows, from strong to weak: carboxyl $>$ inner ester $>$ phenolic hydroxyl group, in which carboxyl may be neutralized by sodium bicarbonate; carboxyl and the inner ester group may be neutralized by sodium carbonate; and carboxyl, the inner ester group and the phenolic hydroxyl group may be neutralized by sodium hydroxide. The analysis results of titration are shown in Table-3.

\begin{tabular}{|c|c|c|c|c|c|}
\hline \multicolumn{6}{|c|}{$\begin{array}{c}\text { TABLE-3 } \\
\text { ANALYSIS RESULTS OF ACID BASE TITRATION AND } \\
\text { BOEHM TITRATION OF SEMI-COKE SAMPLES }\end{array}$} \\
\hline \multirow{2}{*}{ Sample } & \multicolumn{2}{|c|}{$\begin{array}{l}\text { Acid-basic titration } \\
\text { functional group } \\
\left.\qquad / \mathrm{mmol} \mathrm{g}^{-1}\right)\end{array}$} & \multicolumn{3}{|c|}{$\begin{array}{l}\text { Boehm titration functional } \\
\left.\text { group } / \mathrm{mmol} \mathrm{g}^{-1}\right)\end{array}$} \\
\hline & $\begin{array}{l}\text { Acidic } \\
\text { functional } \\
\text { group }\end{array}$ & $\begin{array}{l}\text { Basic } \\
\text { functional } \\
\text { group }\end{array}$ & Carboxyl & Lactones & $\begin{array}{l}\text { Phenolic } \\
\text { hydroxyl }\end{array}$ \\
\hline NM-SC & 0.00836 & 0.00462 & 0.1550 & 0.0304 & 0.0264 \\
\hline $\mathrm{Cl}-\mathrm{SC}$ & 0.01124 & 0.00072 & 0.6347 & 0.0079 & 0.0771 \\
\hline N-SC & 0.01020 & 0.00096 & 0.5890 & 0.0307 & 0.0407 \\
\hline S-SC & 0.01124 & 0.00014 & 0.2920 & 0.0393 & 0.0029 \\
\hline
\end{tabular}

It may be seen that crude semi-coke is rich in the surface acid-base functional group and after being treated with various acids, the content of the acidity functional group on the semicoke surface increases drastically, which indicates that the acid treating process damages the original basicity functional group on the surface and generates a new acidity functional group.

Different acid treatment processes have great effects on the categories and contents of the acidity functional group on the semi-coke surface. Allwar ${ }^{12}$ found modification of the surface chemistry of activated carbon using chemical treatments with nitric acid increased the number of total acid groups. Furthermore, reaction between nitric acid and activated carbons sharply increased the total acid groups containing of carboxylic, lactonic and phenolic groups as oxygen-surface functional groups. Compared with the crude semi-coke, the contents of carboxyl and the phenolic hydroxyl group on the Cl-SC surface increase, while the content of the inner ester group decreases; the contents of carboxyl and the phenolic hydroxyl group on the N-SC surface increase, while that of the inner ester group remains unchanged. The contents of carboxyl and the inner ester group on S-SC surface increase, while that of the phenolic hydroxyl group decreases. On the whole, the different acid treatment processes lead to the result that the content of the carboxyl functional group with strong acidity on the semi-coke surface increases and that semi-coke presents clear acidity. The content of the carboxyl functional group on the semi-coke surface undergoes the largest increase after the $\mathrm{HCl}$ treatment. These results are consistent with the conclusions made by Zhou et al. ${ }^{10}$.

\section{Study on removal of gaseous $\mathbf{H g}^{\mathbf{0}}$}

Analysis of mercury removal property at an adsorption temperature of $30^{\circ} \mathbf{C}$ : In Fig. 2, under the conditions that the inlet mercury concentration is $30 \mu \mathrm{g} / \mathrm{m}^{3}$, gas flow is $1 \mathrm{~L} / \mathrm{min}$, adsorbent is $0.50 \mathrm{~g}$ and adsorbent temperature is $30{ }^{\circ} \mathrm{C}$, the gaseous $\mathrm{Hg}^{0}$ removal effects caused by the crude semi-coke and that treated with various acids are described. It is observed that when the adsorbent temperature is low, the NM-SC has a strong mercury removal performance. The sulfuric acid 
treatment sharply decreases the mercury removal performance of the semi-coke. Compared with the NM-SC, the initial mercury removal efficiency and that after $140 \mathrm{~min}$ of the S-SC, respectively decrease to 0.086 and 0.037 . The hydrochloric acid treatment slightly decreases the mercury removal efficiency of the semi-coke, while the nitric acid treatment slightly increases the efficiency. At a low temperature, gaseous $\mathrm{Hg}^{0}$ takes physisorption as primary on the semi-coke surface. The gaseous $\mathrm{Hg}^{0}$ is primarily absorbed in the micropores on the semi-coke surface. Therefore, the micropore number and structure on the semi-coke surface are the principal factors determining the adsorption efficiency of the gaseous $\mathrm{Hg}^{0}$. The analysis data of the specific surface area and pore structure shows that the crude semi-coke has a relatively large specific surface area and pore volume and the surface micropore proportion has reached $72.4 \%$, thus it has a relatively strong mercury removal efficiency. The sulfuric acid treatment process mainly damages the micropore structure, causing a sharp decrease of the mercury removal efficiency of the semi-coke at a low temperature. Bai et al. ${ }^{13}$ have investigated the influences of hydrochloric acid and nitric acid on the surface areas and pore parameters of activated carbon and their results show that both the surface area and the pore volume of activated carbon increase after acid treatment, whereas nitric acid mainly increases the micropore proportion and volume. In our studies, similar conclusions were obtained. The hydrochloric acid treatment enables the specific surface area and total pore volume of the semi-coke to increase slightly, while the micropore proportion and pore volume decrease by a certain extent, resulting in the decrease of the mercury removal efficiency of the semi-coke. The specific surface area, micropore proportion and pore volume increase after the semi-coke is treated with nitric acid, which is beneficial to the physisorption of $\mathrm{Hg}^{0}$ and may improve the mercury removal efficiency of the semi-coke at a low temperature.

Analysis of mercury removal property at an adsorption temperature of $140{ }^{\circ} \mathrm{C}$ : In Fig. 3 , under the condition that the inlet mercury concentration is $30 \mu \mathrm{g} / \mathrm{m}^{3}$, the gas flow is $1 \mathrm{~L} / \mathrm{min}$, adsorbent is $0.50 \mathrm{~g}$ and adsorbent temperature is

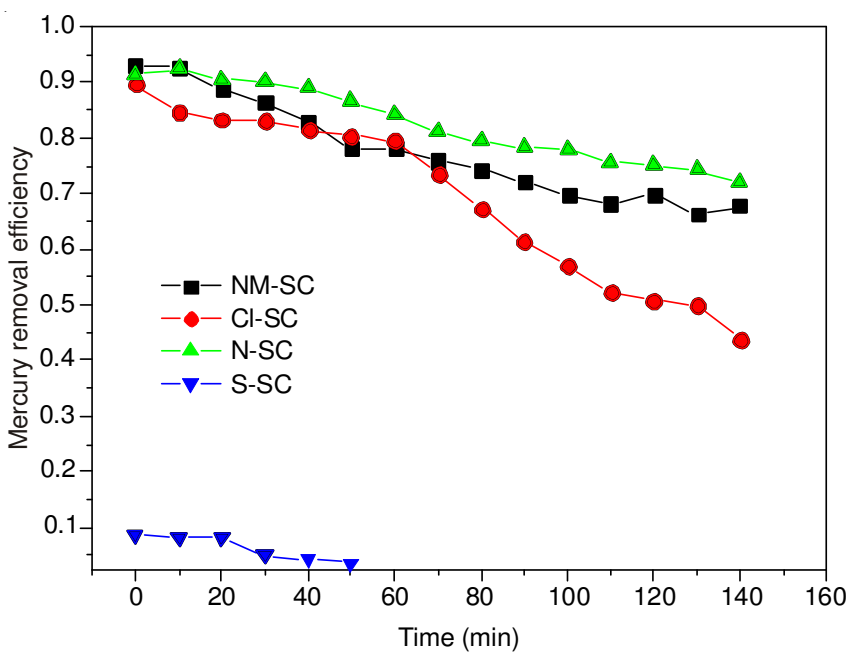

Fig. 2. Mercury removal efficiencies of NM-SC, Cl-SC, N-SC and S-SC at $30{ }^{\circ} \mathrm{C}$

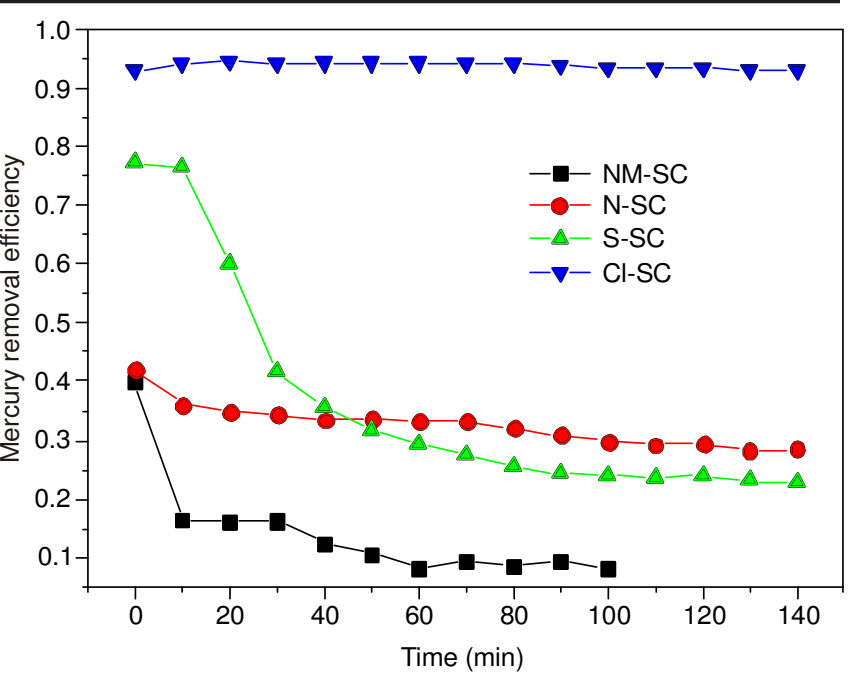

Fig. 3. Mercury removal efficiencies of NM-SC, Cl-SC, N-SC and S-SC at $140{ }^{\circ} \mathrm{C}$

$140{ }^{\circ} \mathrm{C}$, the gaseous $\mathrm{Hg}^{0}$ removal effects caused by the crude semi-coke and those treated with various acids are described. It is observed that when the adsorbent temperature is high, NM-SC has poor mercury removal performance, the $\mathrm{H}_{2} \mathrm{SO}_{4}$ and $\mathrm{HNO}_{3}$ treatments improve the mercury removal efficiency of the semi-coke by a certain degree and the $\mathrm{HCl}$ treatment vastly improves the mercury removal efficiency of the semicoke. After adsorption reaction persists for $140 \mathrm{~min}$, its mercury removal efficiency remains above 0.93 . At a high temperature, chemical adsorption is taken as the main method for gaseous $\mathrm{Hg}^{0}$ on the semi-coke surface. The categories and contents and other chemical properties are the principal factors affecting the mercury removal efficiency of the semi-coke.

According to Morris ${ }^{14}, \mathrm{H}_{2} \mathrm{SO}_{4}$ have relatively strong oxidability and the carbon atoms at the edges and defects of the active carbon and carbon crystal surface may be oxidized to the oxygen-containing functional groups such as the carboxylic group or carbonyl group. Sulfuric acid treatment can substantially increase $\mathrm{Hg}$ uptake by adsorption, particularly in the presence of oxygen. In the present paper, it is found through experiments that plentiful oxygen-containing functional groups such as $\mathrm{H}-\mathrm{O}, \mathrm{C}=\mathrm{O}$ and $\mathrm{C}=\mathrm{O}$ are generated on the semi-coke surface in the $\mathrm{H}_{2} \mathrm{SO}_{4}$ and $\mathrm{HNO}_{3}$ treating processes, as are heteroatom group containing sulfur and nitrogen. As a result, it is inferred that the oxidation mechanism of the partial oxygen-containing functional group on the semi-coke surface is as shown in Fig. 4.

An oxidation-reduction reaction between the $\mathrm{C}=\mathrm{O}$ bond and delocalized electron $p$ and $\mathrm{Hg}^{0}$ is produced, $\mathrm{Hg}^{0}$ is oxidized to $\mathrm{Hg}^{2+}$. A chelation reaction is produced between $\mathrm{Hg}^{2+}$ and carboxyl, the inner ester group and the phenolic hydroxyl group and generates a stable organic complex, which enables the mercury to be absorbed on the semi-coke surface in oxidized form. The study results produced by Rios et al..$^{15}$ and others also show that the carboxyl on the active carbon surface may react chemically with metal ions, thus improving its adsorption capacity adsorbing metal ions. It is inferred that the reaction mechanism between the oxygen-containing functional group and $\mathrm{Hg}^{2+}$ is shown in Fig. 5. 

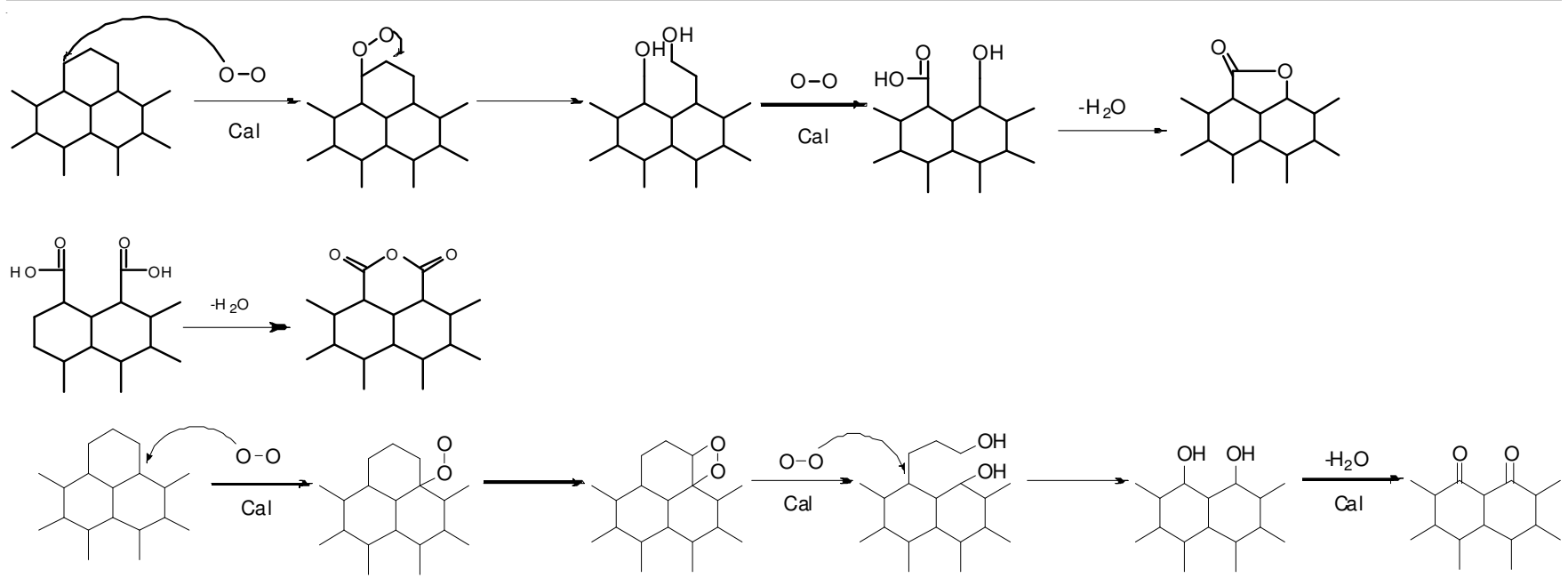

Fig. 4. Suggested model for oxidation mechanism of the partial oxygen-containing functional group on the semi-coke surface

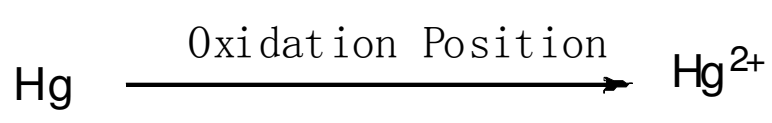<smiles>CC1CCC(C)C2C(C(=O)O)C(C)C(C)C(C)C12</smiles><smiles>CC1CCC(C)C2C1C(C)C(C)C(C)C2C1COO1</smiles><smiles>CC1C(C)C2C(=O)OC(=O)C(C1C)C(C)C(C)C2C</smiles><smiles>CC1C(C)C(C(=O)O)C2C(C(=O)O)C(C)C(C)C(C)C2C1C</smiles><smiles>CC1C(C)C2OC(=O)C3C(C)C(C)C(C)C(C1C)C23</smiles><smiles>[2H]OC(=O)C1C(C)C(C)C(C)C2C(C)C(C)C(C)C(O)C12</smiles><smiles>CC1C(C)C(O)C2C(O)C(C)C(C)C(C)C2C1C</smiles><smiles>C[18OH]</smiles><smiles>CC1C(C)C(O)C2C(O)C(C)C(C)C(C)C2C1C</smiles>

$\mathrm{Hg}$<smiles>CC1C(=O)C2C(C)C(C)C(C)C(C)C2C(=O)C1C</smiles>

Fig. 5. Suggested model for reaction mechanism between $\mathrm{Hg}^{2+}$ and the partial oxygen-containing functional group

The nitrogen-containing functional groups with positiveion positive charges, such as $\mathrm{C}=\mathrm{N}$, pyridine, pyridine- $\mathrm{N}$-oxide, are generated on the semi-coke surface in the nitric acid treating process. The groups may link with $\mathrm{Hg}^{0}$ through induction to form ion dipoles and constitute a dipolar bond with the outermost electron of $\mathrm{Hg}^{0}$ and may also promote the chemical adsorption of $\mathrm{Hg}^{0}$ to a certain degree.

From the above analysis, it is known that the $\mathrm{H}_{2} \mathrm{SO}_{4}$ and $\mathrm{HNO}_{3}$ treatments increase the contents of the oxygen-containing functional groups such as carboxyl, carbonyl and the phenolic hydroxyl groups on the semi-coke surface. In addition, the $\mathrm{HNO}_{3}$ treatment also produces the oxygen-containing functional group with a positive-ion positive charge on the semi-coke surface and these groups will provide active sites for the catalytic oxidation and chemical adsorption of gaseous $\mathrm{Hg}^{0}$, thus improving the mercury removal performance of the semi-coke at $140{ }^{\circ} \mathrm{C}$ to a certain degree.

The $\mathrm{HCl}$ treatment causes the increase of the contents of the functional groups such as carboxyl and the phenolic hydroxyl group on the semi-coke surface and in the modification process, the $\mathrm{Cl}^{-}$in the hydrochloric acid solution produces an ion exchange reaction on the semi-coke surface, thus enabling partial chlorine elements to be absorbed on the semi-coke surface and forming the $\mathrm{Cl}-\mathrm{C}-\mathrm{Cl}$ functional group. When the concentration of the $\mathrm{Cl}^{-}$on the semi-coke surface is high, then $\mathrm{Hg}^{0}$ will react with $\mathrm{Cl}^{-}$and produce the chlorides including mercury, such as $[\mathrm{HgCl}]^{+}, \mathrm{HgCl}_{2}$ or $\left[\mathrm{HgCl}_{4}\right]^{2-16,17}$. The reaction mechanism is described as reactions (2)-(4):

$$
\begin{gathered}
\mathrm{Hg}+[\mathrm{Cl}]^{-} \rightarrow[\mathrm{HgCl}]^{+}+2 \mathrm{e} \\
\mathrm{Hg}+2[\mathrm{Cl}]^{-} \rightarrow\left[\mathrm{HgCl}_{2}\right]+2 \mathrm{e} \\
{\left[\mathrm{HgCl}_{2}\right]+2\left[\mathrm{Cl}^{-}\right] \rightarrow\left[\mathrm{HgCl}_{4}\right]^{2-}}
\end{gathered}
$$

The $\mathrm{C}=\mathrm{O}$ bond on the semi-coke surface and delocalized electron may also be taken as electron acceptors, thus enabling the reaction between $\mathrm{Hg}^{0}$ and $\mathrm{Cl}^{-}$to be conducted towards the positive direction and generating the stable chloride of mercury. The oxygen-containing functional group and chlorine-containing group shaped on the semi-coke surface after the $\mathrm{HCl}$ treatment may provide an active site for the oxidation and chemical adsorption of gaseous $\mathrm{Hg}^{0}$ and due to the fact that mercury is prone to reacting chemically with chlorine with a high reaction rate, the HCI treatment may remarkably increase the mercury removal efficiency of the semi-coke at $140{ }^{\circ} \mathrm{C}$. 


\section{Conclusion}

The acid treating process has a relatively significant effect on the surface physico-chemical properties of the crude semicoke. When the adsorbent temperature is $30{ }^{\circ} \mathrm{C}$, compared with the crude semi-coke, the mercury removal efficiency of the S-SC decreases sharply and the efficiency of the Cl-SC decreases slightly, while that of the N-SC increases slightly; when the adsorbent temperature is $140^{\circ} \mathrm{C}$, the mercury removal efficiencies of the three acids are higher than those of the crude semi-coke, in which that of the $\mathrm{Cl}-\mathrm{SC}$ is increased by the largest degree. The $\mathrm{C}=\mathrm{O}$ bond and delocalized electron and nitrogencontaining functional group with positive charge on the surfaces of the S-SC and N-SC may be taken as the oxidized electron acceptors of the gaseous $\mathrm{Hg}^{0}$. The oxidation-state $\mathrm{Hg}^{2+}$ further generates a chelation reaction with groups such as carboxyl, the inner ester group and the phenolic hydroxyl group, produces a stable organic complex. The $\mathrm{Cl}-\mathrm{C}-\mathrm{Cl}$ functional group on the surface of the $\mathrm{Cl}-\mathrm{SC}$ is prone to generating a chemical reaction with $\mathrm{Cl}$ and the $\mathrm{C}=\mathrm{O}$ bond and delocalized electron may also be taken as electron acceptors, thus promoting the reaction to be conducted towards the positive direction and causing stable chlorides to be absorbed on the semi-coke surface.

\section{ACKNOWLEDGEMENTS}

This study was supported by the National Natural Science Foundation of China (No. 21006059, 51406107) and the Project of Shandong Province Higher Educational Science and Technology Program (J11LB61).

\section{REFERENCES}

1. K. Sundseth, J.M. Pacyna, E.G. Pacyna, J. Munthe, M. Belhaj and S. Astrom, J. Clean. Prod., 18, 386 (2010).

2. N. Pirrone, S. Cinnirella, X. Feng, R.B. Finkelman, H.R. Friedli, J. Leaner, R. Mason, A.B. Mukherjee, G.B. Stracher, D.G. Streets and K. Telmer, Atmos. Chem. Phys., 10, 5951 (2010).

3. J. Liu, W.Q. Qu and C.G. Zheng, Proc. Combust. Inst., 34, 2811 (2013).

4. S.S. Lee, J.Y. Lee and T.C. Keener, Fuel Process. Technol., 90, 1314 (2009).

5. J.W. Wang, J.L. Yang and Z.Y. Liu, Fuel Process. Technol., 91, 676 (2010).

6. Z.Q. Tan, L.S. Sun, J. Xiang, H. Zeng, Z. Liu, S. Hu and J. Qiu, Carbon, 50, 362 (2012).

7. H.W. Zhang, J.T. Chen, P. Liang and L. Wang, J. Environ. Sci., 24, 2083 (2012).

8. J. Liu, M.A. Cheney, F. Wu and M. Li, J. Hazard. Mater., 186, 108 (2011).

9. J. Gao, C.H. Li and J.J. Bian, J. Ocean Univ. China, 41, 61 (2011).

10. H.Y. Zhou, L. Shi and Q. Sun, Chin. J. Catal., 33, 1463 (2012).

11. V. Strelko Jr., D.J. Malik and M. Streat, Carbon, 40, 95 (2002).

12. A. Allwar, IOSR J. Appl. Chem., 2, 9 (2012).

13. Z.Q. Bai, H.K. Chen, W. Li and B.Q. Li, J. China Univ. Mining Technol., 35, 246 (2006).

14. E.A. Morris, D.W. Kirk, C.Q. Jia and K. Morita, Environ. Sci. Technol., 46, 7905 (2012).

15. R.R.V.A. Rios, D.E. Alves, I. Dalmázio, S.F.V. Bento, C.L. Donnici and R.M. Lago, Mater. Res., 6, 129 (2003).

16. S.S. Tao, C.T. Li, X.P. Fan, G. Zeng, P. Lu, X. Zhang, Q. Wen, W. Zhao, D. Luo and C. Fan, Chem. Eng. J., 210, 547 (2012).

17. S. Eswaran, H.G. Stenger and Z. Fan, Energy Fuels, 21, 852 (2007). 